\title{
Research antioxidant activity of chitooligosacchride by UV- VIS absorption spectrocopy
}

\author{
Bui Van Hoai ${ }^{1 *}$, Ngo Dai Nghiep ${ }^{1}$, Dao An Quang ${ }^{2}$, Nguyen Thi Nam Phuong ${ }^{2}$ \\ ${ }^{1}$ University of Science, Viet Nam National University Ho Chi Minh City, Vietnam \\ ${ }^{2}$ Ho Chi Minh City University of Food Industry, Vietnam \\ *Corresponding author: hoaibv@cntp.edu.vn
}

\begin{tabular}{|c|c|}
\hline ARTICLE INFO & ABSTRACT \\
\hline COUJS. & $\begin{array}{l}\text { Chitosan with } 80 \% \text { degree of deacetylation was hydroly } \\
\text { by cellulase of Trichoderma viride to pre }\end{array}$ \\
\hline Received: February 0 & with ultrafiltration membrane. The antioxidant activities of the \\
\hline Revised: & COSs were clarified in this study by reducing power and free \\
\hline Accepted: April 16 ${ }^{\text {th }}, 2018$ & $\begin{array}{l}\text { radical scavenging ability assay by UV-VIS absorption spectrum. } \\
\text { The results show that the COS } 1(10,000-5,000 \text { Da), COS } 2\end{array}$ \\
\hline $\begin{array}{l}\text { Keywords: } \\
\text { antioxidant, } \\
\text { chitooligosaccharide, DPPH, } \\
\text { reducing power, UV-VIS }\end{array}$ & $\begin{array}{l}(5,000-3,000 \mathrm{Da}), \operatorname{COS} 3(3,000-1,000 \mathrm{Da}) \text { and COS } 4 \text { (less } \\
\text { than1,000 Da) segments have antioxidant properties. The } \\
\text { antioxidant activities of the COSs increased with the increment of } \\
\text { concentration, and they also depended on molecular weight. }\end{array}$ \\
\hline
\end{tabular}

\section{Introduction}

Chitosan is a derivative of chitin, which is a naturally abundant mucopolysaccharide and distributes in the shell of crustaceans, in the cuticle of insects, and also in the cell wall of some fungi and microorganisms. The molecular structure of chitosan consists of two units of $\mathrm{N}$-acetylglucosamine and glucosamine. Chitosan has attracted much attention during past decades because of a lot of their bio-activity as anti-bacterial, anti-fungi, anti-inflammation. However, chitosan shows its bio-activity only in acidic medium and it is not soluble in water. These reasons caused the limitation of chitosan applications in fields. Therefore, converting chitosan into chitooligosaccharides (COSs) with a high soluble degree in water has been a concern by many researchers. COSs have important biological properties in medicinal and pharmaceutical applications such as antioxidative, anti-bacterial, immuno-stimulant, adipogenesis inhibitory and anticancer activities (Jeon \& Kim, 2000; Kim \& Rajapakse, 2005).

Free radicals cause oxidation that reduces the quality of food products. Chemical synthetic antioxidants have free radical scavenging ability. However, the use of synthetic antioxidants in food products must conform to strict food safety regulations due to their potential health hazards. COSs with free radical scavenging ability is a natural compound in the prevention of oxidation. However, the free radical scavenging ability of COSs depends on their molecular weights (Park, Je, \& Kim, 2003). Therefore, in this study, the free radical scavenging activity of COSs was investigated to clarify this problem. 


\section{Materials and methods}

\subsection{Materials}

Chitosan (degree of deacetylation more than $80 \%$, Viet Nam). Cellulase (Fungal cellulase, $4000 \mathrm{UI} / \mathrm{g}$, Trichoderma viride), India). Lactic acid (India), $\mathrm{NaHCO}_{3}$ (India), [DPPH] 2,2-Diphenyl-1-picrylhydrazyl (Sigma), [BHT] butylated hydroxytoluene (India), Ascorbic acid (India), [TCA] trichloroacetic acid (India), $\left[\mathrm{K}_{3} \mathrm{Fe}(\mathrm{CN})_{6}\right]$ potassium ferricyanide (India), Phosphate buffer (India), Ethanol (China), $\left[\mathrm{FeCl}_{3}\right]$ ferric chloric (India), Sodium hydroxyl (China).

Instrument: Spectrophotometer of model 6600 UV-VIS (WTW-Germany).

\subsection{Methods}

\subsubsection{Preparation of $\mathrm{COSS}$}

COSs solution was created from our previous research (Bui et al., 2017) Briefly, 0.8\% chitosan solution was prepared in $0.8 \%$ lactic acid solution. A $0.8 \%$ chitosan solution was hydrolyzed by cellulase with optimum parameters as $50^{\circ} \mathrm{C}, \mathrm{pH}$ of $5.5,7$ UI cellulase and hydrolysis time of 180 minutes. COSs after hydrolysis was filtered through an ultrafiltration membrane with molecular weight cut-offs (MWCO) of 10, 5, 3, and $1 \mathrm{kDa}$ to fractionate COSs into four kinds. COS 1 are oligosaccharides passing through the $10 \mathrm{kDa}$ membrane but not through the $5 \mathrm{kDa}$ membrane. COS 2 are oligosaccharides passing through the $5 \mathrm{kDa}$ membrane but not through the $3 \mathrm{kDa}$ membrane. COS 3 are oligosaccharides passing through the $3 \mathrm{kDa}$ membrane but not through the $1 \mathrm{kDa}$ membrane. COS 4 are oligosaccharides passing through the $1 \mathrm{kDa}$ membrane. COSs fractionation was carried out spray drying (SD-06AG, LabPlant, UK) to create COSs powder (Park et al., 2003).

\subsubsection{DPPH radical scavenging ability assay}

The DPPH radical scavenging ability of COSs was measured using the modified method of Blois (1958) (Blois, 1958) described by Matute et al. (2013). Briefly, $1.5 \mathrm{~mL}$ of DPPH solution $(40 \mu \mathrm{g} / \mathrm{mL}$, dissolved in ethanol of $99 \%)$ was mixed with $1 \mathrm{~mL}$ of COSs (different concentrations from 1 to $5 \mathrm{mg} / \mathrm{mL}$, dissolved in water). The mixture was vortexed in $15 \mathrm{~s}$ and incubated at room temperature for $30 \mathrm{~min}$. The absorbance of the mixture was measured at a wavelength of $517 \mathrm{~nm}$. Butylated hydroxytoluene and ascorbic acid were used as the positive control sample. The DPPH activity was calculated as an inhibition percentage based on the following equation:

DPPH free radical scavenging activity $(\%)=\left(1-\mathrm{Abs}_{\text {sample }} / \mathrm{Abs}_{\mathrm{control}}\right) * 100$.

where $\mathrm{Abs}_{\text {sample }}$ and $\mathrm{Abs}_{\text {control }}$ are the absorbance of the sample and control, respectively.

EC50/IC 50 value is defined as the number of antioxidants necessary to decrease the absorbance of DPPH by $50 \%$ of the initial absorbance. 


\subsubsection{Reducing power assay}

The reducing power of the COSs was determined by the method of Oyaizu (1986) and described by Yen and Chen (1995). Briefly, samples were prepared in different concentrations ( $1 \mathrm{~mL}, 1$ to $5 \mathrm{mg} / \mathrm{mL}$ ) and mixed with phosphate buffer $(2.5 \mathrm{~mL}, 0.2 \mathrm{M}, \mathrm{pH} 6.6)$ and potassium ferricyanide $\left[\mathrm{K}_{3} \mathrm{Fe}(\mathrm{CN})_{6}\right](2.5 \mathrm{~mL}, 1 \%)$. The mixture was incubated at $50^{\circ} \mathrm{C}$ for $20 \mathrm{~min}$. Trichloroacetic acid $(2.5 \mathrm{~mL}, 10 \%)$ was added to the mixture and then centrifuged for $10 \mathrm{~min}$ at $3000 \mathrm{rpm}$. An aliquot from upper layer $(2.5 \mathrm{~mL})$ was diluted with $2.5 \mathrm{~mL}$ distilled water and $0.5 \mathrm{~mL}$ of $0.1 \% \mathrm{FeCl}_{3}$. The absorbance was measured at a wavelength of $700 \mathrm{~nm}$. Butylated hydroxytoluene and ascorbic acid were used as the positive control sample. Reducing power was calculated based on the following equation:

$$
\text { Reducing power }=\text { Abs } 1-\text { Abs2 }
$$

where Abs1 is the absorbance of the sample and Abs2 is the absorbance of the sample under identical conditions as $\mathrm{Abs} 1$ with water instead of $\mathrm{FeCl}_{3}$ solution only. A higher absorbance indicates a higher reducing power.

\subsubsection{Statistical analysis}

Data were expressed as the mean \pm standard deviation (SD) of triplicates. The least significant difference (LSD), Duncan's multiple range test, and one-way analysis of variance (ANOVA) was used for multiple comparisons by Statgraphic centurion. The difference was considered to be statistically significant if $\mathrm{p}<0.05$.

\section{Results and discussion}

\subsection{Preparation of COSs}

A powder of COSs were successfully prepared using a UF membrane with four different membranes as the COS 1 (10,000-5,000 Da), COS 2 (5,000-3,000 Da), COS 3 (3,000-1,000 Da) and COS 4 (less than1,000 Da). The COSs were determined antioxidant activity through the DPPH free radical scavenging ability and reducing power by UV-Vis spectrophotometry. 


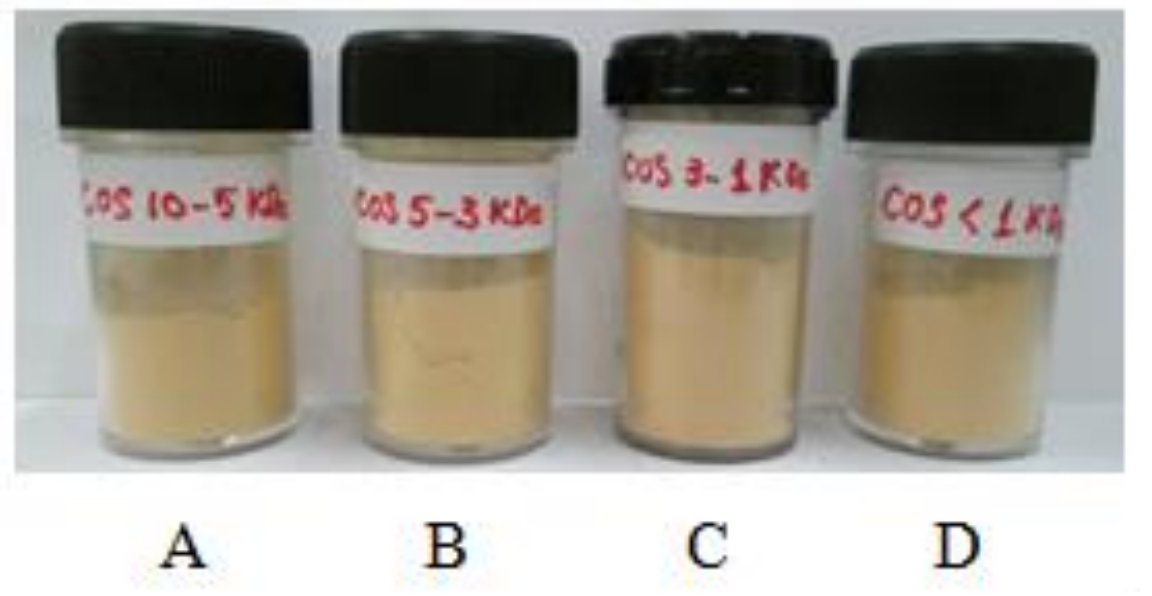

Figure 1. Powder of COSs

Note: (A) COS 1, oligosaccharides that are passed through the $10 \mathrm{kDa}$ membrane but not through the $5 \mathrm{kDa}$ membrane; (B) COS 2, oligosaccharides that are passed through the $5 \mathrm{kDa}$ membrane but not through the $3 \mathrm{kDa}$ membrane; (C) COS 3, oligosaccharides that are passed through the $3 \mathrm{kDa}$ membrane but not through the $1 \mathrm{kDa}$ membrane; (D) COS 4, oligosaccharides that are passed through the $1 \mathrm{kDa}$ membrane. COSs fractionation were carred out spray drying to created COSs powder

\subsection{DPPH radical scavenging ability}

The DPPH radical scavenging ability of COSs was shown in Table 1. Results showed that COSs had DPPH radical scavenging ability. At the same concentration, the DPPH radical scavenging ability of COS 3 is the highest. The COSs activity increased from COS 1 to COS 3 and depended on the increment of their concentration from $1 \mathrm{mg} / \mathrm{mL}$ to $5 \mathrm{mg} / \mathrm{mL}$. The DPPH activity of the COS 3 is highest with $76.61 \pm 1.64 \%$ at $5 \mathrm{mg} / \mathrm{mL}$. This result is lower than the research of Park et al. (2003) with $96.79 \%$ at $5 \mathrm{mg} / \mathrm{mL}$. This result showed that the free radical scavenging ability is enhanced with increased concentration and reduced molecular weight. A value of IC 50 of COS 3 and COS 4 is $3 \mathrm{mg} / \mathrm{mL}$.

\section{Table 1}

DPPH radical scavenging ability of COSs (\%)

\begin{tabular}{ccccc}
\hline $\begin{array}{c}\text { Concentration } \\
\mathbf{m g} / \mathbf{m L}\end{array}$ & $\operatorname{COS} \mathbf{C}$ & $\operatorname{COS} 2$ & $\operatorname{COS~3}$ & $\operatorname{COS~4}$ \\
\hline 1 & $17.61 \pm 2.98^{\mathrm{d}}$ & $23.99 \pm 1.79^{\mathrm{c}}$ & $31.74 \pm 1.39^{\mathrm{a}}$ & $28.12 \pm 3.29^{\mathrm{b}}$ \\
2 & $31.82 \pm 2.31^{\mathrm{d}}$ & $36.93 \pm 1.09^{\mathrm{c}}$ & $48.43 \pm 3.33^{\mathrm{a}}$ & $45.21 \pm 2.38^{\mathrm{b}}$ \\
3 & $44.44 \pm 0.68^{\mathrm{d}}$ & $49.80 \pm 2.30^{\mathrm{c}}$ & $56.09 \pm 2.65^{\mathrm{a}}$ & $53.60 \pm 2.07^{\mathrm{b}}$ \\
4 & $53.79 \pm 1.88^{\mathrm{d}}$ & $58.39 \pm 0.86^{\mathrm{c}}$ & $65.87 \pm 0.45^{\mathrm{a}}$ & $62.18 \pm 2.80^{\mathrm{b}}$ \\
5 & $61.36 \pm 1.42^{\mathrm{d}}$ & $65.28 \pm 2.08^{\mathrm{c}}$ & $76.61 \pm 1.64^{\mathrm{a}}$ & $71.82 \pm 1.16^{\mathrm{b}}$ \\
\hline
\end{tabular}

Note: Values represent the mean $\pm \mathrm{SD}, \mathrm{n}=3$, abcd are mean value of rows, statistically significant defference with $\mathrm{p}<0.05$. COS 1, oligosaccharides that are passed through the $10 \mathrm{kDa}$ membrane but not through the $5 \mathrm{kDa}$ membrane; $\operatorname{COS~2,~oligosaccharides~that~are~passed~through~the~} 5 \mathrm{kDa}$ membrane but not through the $3 \mathrm{kDa}$ 
membrane; $\operatorname{COS~3,~oligosaccharides~that~are~passed~through~the~} 3 \mathrm{kDa}$ membrane but not through the $1 \mathrm{kDa}$ membrane; and $\operatorname{COS~4,~oligosaccharides~that~are~passed~through~the~} 1 \mathrm{kDa}$ membrane.

Source: The researcher's data analysis

Table 2

DPPH radical scavenging ability of ascorbic acid and BHT (\%)

\begin{tabular}{ccc}
\hline Concentration $\boldsymbol{\mu g} / \mathbf{m L}$ & Ascorbic acid & BHT \\
\hline 1000 & $97.18 \pm 1.67$ & $79.56 \pm 1.06$ \\
500 & $94.23 \pm 1.34$ & $76.81 \pm 1.10$ \\
250 & $89.03 \pm 1.42$ & $72.98 \pm 1.07$ \\
100 & $85.09 \pm 1.24$ & $69.56 \pm 1.05$ \\
50 & $76.78 \pm 1.29$ & $65.34 \pm 1.39$ \\
$\mathbf{2 5}$ & $\mathbf{6 2 . 4 5} \pm \mathbf{1 . 0 2}$ & $\mathbf{5 6 . 2 3} \pm \mathbf{1 . 3 3}$ \\
12.5 & $46.35 \pm 1.05$ & $40.12 \pm 1.22$ \\
\hline
\end{tabular}

Note: Values represent the mean $\pm \mathrm{SD}, \mathrm{n}=3$

Source: The researcher's data analysis

\subsection{Reducing power}

The COSs powder was dissolved in water into different concentrations of $1 \mathrm{mg} / \mathrm{mL}$ to $5 \mathrm{mg} / \mathrm{mL}$ and determined reducing power showed in Table 3. The reducing ability of the COS 4 is highest with absorbance increased from $0.120 \pm 0.009$ Abs to $0.432 \pm 0.014$ Abs with increasing concentration from $1 \mathrm{mg} / \mathrm{mL}$ to $5 \mathrm{mg} / \mathrm{mL}$. The absorbance was recorded at $5 \mathrm{mg} / \mathrm{mL}$ of COS 1, COS 2 and COS 3 with reducing power $0.297 \pm 0.007 \mathrm{Abs}, 0.309 \pm 0.004 \mathrm{Abs}$ and $0.423 \pm 0.020 \mathrm{Abs}$, respectively. The reducing power results of COSs showed that their reducing ability depended on their molecular weight and concentration. However, this activity is still lower than the reducing ability of ascorbic acid and BHT (shown Table 4).

\section{Table 3}

Reducing power of COSs by absorbance value (Abs)

\begin{tabular}{ccccc}
\hline $\begin{array}{c}\text { Concentration } \\
\mathbf{m g} / \mathbf{m L}\end{array}$ & COS 1 & COS 2 & COS 3 & COS 4 \\
\hline 1 & $0.092 \pm 0.007^{\mathrm{d}}$ & $0.107 \pm 0.004^{\mathrm{c}}$ & $0.112 \pm 0.010^{\mathrm{b}}$ & $0.120 \pm 0.009^{\mathrm{a}}$ \\
2 & $0.144 \pm 0.011^{\mathrm{d}}$ & $0.153 \pm 0.006^{\mathrm{c}}$ & $0.166 \pm 0.002^{\mathrm{b}}$ & $0.218 \pm 0.03^{\mathrm{a}}$ \\
3 & $0.190 \pm 0.006^{\mathrm{d}}$ & $0.209 \pm 0.009^{\mathrm{c}}$ & $0220 \pm 0.011^{\mathrm{b}}$ & $0.272 \pm 0.032^{\mathrm{a}}$ \\
\hline
\end{tabular}




\begin{tabular}{ccccc}
$\begin{array}{c}\text { Concentration } \\
\mathbf{m g} / \mathbf{m L}\end{array}$ & COS 1 & COS 2 & COS 3 & COS 4 \\
\hline 4 & $0.234 \pm 0.009^{\mathrm{d}}$ & $0.246 \pm 0.006^{\mathrm{c}}$ & $0.332 \pm 0.015^{\mathrm{b}}$ & $0.346 \pm 0.006^{\mathrm{a}}$ \\
5 & $0.297 \pm 0.007^{\mathrm{d}}$ & $0.309 \pm 0.004^{\mathrm{c}}$ & $0.423 \pm 0.020^{\mathrm{b}}$ & $0.432 \pm 0.014^{\mathrm{a}}$ \\
\hline
\end{tabular}

Note: Values represent the mean $\pm S D, n=3$, abcd are mean value of row, statistically significant difference with $\mathrm{p}<0.05$. COS 1, oligosaccharides that are passed through the $10 \mathrm{kDa}$ membrane but not through the $5 \mathrm{kDa}$ membrane; $\operatorname{COS~2,~oligosaccharides~that~are~passed~through~the~} 5 \mathrm{kDa}$ membrane but not through the $3 \mathrm{kDa}$ membrane; $\operatorname{COS~3,~oligosaccharides~that~are~passed~through~the~} 3 \mathrm{kDa}$ membrane but not through the $1 \mathrm{kDa}$ membrane; and $\operatorname{COS} 4$, oligosaccharides that are passed through the $1 \mathrm{kDa}$ membrane.

Source: The researcher's data analysis

Table 4

Reducing power of ascorbic acid and BHT by absorbance value (Abs)

\begin{tabular}{ccc}
\hline Concentration $\boldsymbol{\mu g} / \mathbf{m L}$ & Ascorbic acid & BHT \\
\hline 1000 & $2.528 \pm 0.018$ & $1.977 \pm 0.095$ \\
500 & $2.449 \pm 0.122$ & $1.808 \pm 0.087$ \\
250 & $2.207 \pm 0.034$ & $1.262 \pm 0.085$ \\
100 & $0.764 \pm 0.025$ & $0.718 \pm 0.070$ \\
50 & $0.418 \pm 0,024$ & $0.329 \pm 0.052$ \\
\hline
\end{tabular}

Note: Values represent the mean $\pm \mathrm{SD}, \mathrm{n}=3$

Source: The researcher's data analysis

\section{Conclusion}

Results of this research showed that the COSs (less than $10 \mathrm{kDa}$ ) had the antioxidant ability. The antioxidant activity depended on their molecular weight and concentration. Because COS 3 and COS 4 activities are highest, the production of COSs powder should focus on molecular weight less than $3000 \mathrm{Da}$. These results suggest that COSs have to apply research in food products to evaluate potentially applicative ability as a natural antioxidant instead of synthesis antioxidant. Although the results of DPPH and reducing power activity of COSs are still lower than BHT and ascorbic acid, they have the potential to be used as antioxidants instead of synthetic antioxidants.

\section{ACKNOWLEDGEMENT}

This research is funded by the Vietnam National Foundation for Science and Technology Development (NAFOSTED) under Grant Number: 106-NN.02- 2014.87. This research is also funded by the Ho Chi Minh City University of Food Industry (HUFI) Foundation under Grant Number: 72/HĐ-DCT. 


\section{References}

Blois, M. S. (1958). Antioxidant determination by the use of a stable free radical. Nature, 181, 1199-1200.

Bui, V. H., Dao, A. Q., Nguyen, T. N. P., Vo, D. N., Tran, T. K. Q., \& Ngo, D. N. (2017). Research of chitosan hydrolysis by cellulase to produce chitooligosaccharide. Journal of Science Technology \& Food, 12(1), 11.

Jeon, Y. J., \& Kim, S. K. (2000). Continuous production of chitooligosaccharides using a dual reactor system. Process Biochemistry, 35(6), 623-632.

Kim, S. K., \& Rajapakse, N. (2005). Enzymatic production and biological activities of chitosan oligosaccharides (COS): A review. Carbohydrate Polymers, 62(4), 357-368.

Matute, A. I. R., Cardelle-Cobas, A., García-Bermejo, A. B., Montilla, A., Olano, A., \& Corzo, N. (2013). Synthesis, characterization and functional properties of galactosylated derivatives of chitosan through amide formation. Food Hydrocolloids, 33(2), 245-255.

Oyaizu, M. (1986). Studies on products of browning reactions: Antioxidative activities of products of browning reaction prepared from glucosamine. Japanese Journal of Nutrition, 44, 307-315.

Park, P. J., Je, J. Y., \& Kim, S. K. (2003). Free radical scavenging activity of chitooligosaccharides by electron spin resonance spectrometry. Journal of Agricultural and Food Chemistry, 51(16), 4624-4627.

Yen, G. C., \& Chen, H. Y. (1995). Antioxidant activity of various tea extracts in relation to their antimut agenicity. Journal of Agricultural and Food Chemistry, 43(1), 27-32. 